\title{
Design Proposal for Product Quality Tracing and Supply Chain Finance Monitoring System Comprehensive Platform
}

\author{
Xiangjun $\mathrm{He}$ \\ School of Safety and Environmental Engineering, Capital University of Economics and Business, \\ Beijing, 100021
}

Keywords: product quality tracing comprehensive platform, supply chain finance

\begin{abstract}
In this paper, a product quality safety tracing system has been established to analyze and evaluate possible hazards from sections of raw material purchase (source) to product processing to consumption. At the same time, a supply chain finance platform has been built to further study safety risk control in the warehouse warrant financing, goods hypothetical financing and accounts receivable financing.
\end{abstract}

\section{Introduction}

Complete product quality safety management should include hazard analysis and identify preventive measures; determine critical control points; identify critical control limits; monitor each critical control point; take corrective actions when the critical limit deviation occurs; develop a record keeping system, establish a review process for analyzing and evaluation of all sections including raw material purchase (source) $\rightarrow$ product processing $\rightarrow$ consumption. Based on these analyzes and assessments, critical control points (CCPS) for the whole process from raw material to final consumption can be set up. Therefore, it must establish an effective monitoring of critical control point program, with the important part being the product quality and safety tracing system.

At the same time, in addition to the establishment of product quality and safety tracing experimental platform, the fund flow will be further expanded on the basis of the entity supply chain, to establish a financial supply chain monitoring and risk control experiment platform, thereby to further study safety risk control in warehouse warrant financing, goods mortgage financing and accounts receivable financing.

\section{Overall Frame}

With the existing supply chain experimental platform, the product quality and safety tracing system including suppliers, manufacturers, retailers, users and third-party logistics will be built, to provide postgraduates and graduate students a complete, modern, flexible, multi-disciplinary sharing multi-purpose experimental platform.

The functions of the experimental platform include:

1) It can basically simulate a whole process tracing of a modern production enterprise production status, process management and quality and safety.

2) It can basically simulate the basic functions containing the upstream, middle stream and 
downstream supply chain logistics tracing and build a supply chain product quality and safety tracing management platform with the supply chain visualization tools.

3) It can basically simulate the most basic function of a financial supply chain risk control and safety management and build an experimental platform for studying financial supply chain risk control methods and tools through the fund flow visualization.

Software and hardware requirements:

It requires suppliers to provide product quality and safety tracing software, the gateway and supply chain visualization software and financial supply chain monitoring and risk control software, while providing hardware required by the tracing system.

Proposals shall be designed with the actual data from enterprises (can be modified) and the supply chain implementation plan based on product quality and safety tracing system must be provided, at least providing the discrete manufacturing and process manufacturing basic data software and hardware executive plan and teaching experimental program.

The platform system shall: 1) support a variety of hardware operating systems. 2) support large databases and open interfaces. 3) support multi-user concurrent use. 4) adopt the B / S structure, with the system maintenance and upgrade finished on the server side. 5) simple operation, friendly interface, flexible operation. 6) software with open interfaces, the system is fully scalable to meet users' future application development. 7) capable of supporting multiple applications in different application environments.

\section{Functional Requirements of the Product Quality and Safety Tracing Platform}

Establish a business model: on the basis of the existing supply chain experimental platform (including MES system) on the scene and according to real production operations to establish a business model to simulate the operation process of the enterprise. The model should have representativeness of relevant industries, do some simplification, and be easy to combine with teaching practice. According to the model established, two sets of typical business data will be extracted from the real operation data of enterprises (reflecting the discrete manufacturing and process manufacturing system characteristics and different from existing data in the system) and such data will be imported into the system platform. Business data should include the following types:

Logistics: physical movement of material goods from suppliers to demanders, including commodity transportation, storage, handling, distribution processing, and related logistics information.

Cash flow: refers to financial matters involved in the process of supply chain transactions.

Information flow: all types of messages associated with the entire supply chain, logistics, capital flow associated, but also part of the logistics and information flow, including purchase orders, inventory records, confirmations, invoices, and quality information.

The quality tracing model needs to be able to simulate the actual process of tracing batches and 
serial number in the practical production, enables crossover tracking and batch expansion tracing, and realize positive and negative material tracing. It can trace the raw materials and also trace from the products back to raw materials.

The quality management data that can meet quality tracing can come from the software simulation data or from other systems. The quality tracing described above shall be realized under the same operating platform.

\section{Gateway and Visualization Functional Requirements}

In order to achieve integrated supply chain finance platform and product quality and safety tracing platform to realize exchange of business transactions data among different types of systems, it is necessary to provide data integration gateway software. The following functions shall be realized:

1) Order visualization: ]the entire supply chain order process visualization, including forecasting, order and order modification collaboration, shipping and receiving, invoicing and payment collaboration.

2) Stock visualization: visualization of each node inventory of the supply chain enterprises, providing details of transporting, inspection, returned or ordered goods.

3) Visualization of logistics: each node of the supply chain logistics is visualized, including shipping and receiving, order tracking, shipping status tracking (including multi-level transport and global logistics), rule-based alerts, and other orders matching or supported the shipping and receiving.

4) Supply chain execution performance: calculate and collect the supply chain performance levels like the complete order fulfillment rates.

\section{Financial Supply Chain and Its Risk Control Monitoring Platform Functions}

Financial supply chain monitoring and risk control platform: containing at least inventory hypothecation, receivables hypothecation and warehouse warrant hypothecation and proposals. Its functions at least contain the supply chain financing platform visualization support, supply chain financing basic information management, and financing before, during and after administration. The specific requirements are as follows:

(1) Visualization support module and functions of the platform

Provide an open data interface, support acquisition of the upstream, middle stream and downstream data of the supply chain in different ways, including the companies to submit data maintained by the Bank. Enterprises input their data via the bank financing platform. Business information systems dock with the enterprise information systems to realize real-time data interaction and update.

Acquisition of enterprise business and financial information on the upstream, middle stream 
and downstream of the supply chain, and realization of fund flow visualization based on the order visualization, inventory visualization and logistics visualization.

The establishment of financial business model and event handling mechanism to monitor important nodes of the supply chain, monitor the implementation of supply chain and logistics execution state, discover and handle abnormal business, to form a basic platform for the safe management of fund flow.

(2) Supply chain information management module and function

Taking the core enterprise as a leader, on each supply chain node including raw material supply, manufacturing, wholesale and retail, it shall be able to analyze and manage the basic information of many SMEs, financial statements, personnel structure, operating conditions as well as manage the overall credit granting of the supply chain and the credit granting limit of a single enterprise in the upstream middle stream and downstream of the supply chain.

1) Credit business prior management module and functions

Credit application management: manage the enterprise loan materials (including the amount of the loan application, duration, type, related guarantees); loan applications assessment: based on credit evaluation index of banks, comparing data from enterprises and evaluating the credit applications so that enterprises conforming to the credit standards can enter the review process. The evaluation contents include the overall evaluation of the supply chain and the evaluation of a single enterprise.

2) Management modules and functions in the credit businesses

Verification management: qualified applications after evaluation can directly enter the bank's internal review process; lending management: including management of approved loan contracts, approval documents, documents related to the mortgage and hypothecation as well as sponsor management; verified cancellation management: management of repayment and verified cancellation, including the five-category classification and identification bad debts. Early warning platform: through monitoring over the implementation of supply chain services to timely discover and make early warning over the credit risk in the supply chain.

3) Functional requirements on application integration gateway system:

Between the upstream and downstream ERP, ERP flat file data or XML data are converted into standard EDI (ANSI X12, EDIFACT) or RosettaNet (XML) for supply chain collaboration. Between ERP and MES, MES executable production plan is generated by the ERP production planning. Between WMS and ERP, standard EDI (ANSI X12, EDIFACT) or RosettaNet (XML) is applied for supply chain collaboration. For integration of MES and production line equipment, production instructions may be received by the device, and production status can be fed back to MES. For RFID, bar code and MES integration, RF or bar code device can drive the operation of the production line. Quality tracing system and ERP systems are integrated. Financial supply chain monitoring and risk control platform are integrated with ERP. Financial supply chain monitoring and risk control platform is integrated with third-party logistics. 
4) Supply chain finance risk control

According to the implementation of supply chain visualization data, modeling is made. The financial supply chain monitoring platform performs monitoring analysis over the supply chain inventory quantity / amount, warehouse warrant and accounts receivable, to perform risk assessment over the entire supply chain operation mode. On this basis, an evaluation system for the enterprise quality rating and loan value on the supply chain will be established to control the financial supply chain risks.

\section{Conclusion}

It shall have the cockpit management functions. The dashboard is used to intuitively display the credit history, financial data, lending and collateral management of the supply chain and the upstream and downstream enterprises, to build a basic platform for financing functional analysis, thereby to evaluate the supply chain executive capacity and health level and evaluate the executive capacity of enterprises as members of the supply chain.

The financial supply chain operations database is used to build a financial supply chain performance analysis model. It takes the cockpit model and uses intuitive dashboards to show the performance of banks through lending to the upstream, middle stream and downstream enterprise on the supply chain by means of reports and charts.

\section{References}

[1] Cao Hailu, Jiao Yi. An introduction to the construction of traceability system for quality and safety of agricultural products at home and abroad, Journal of traditional Chinese Medicine 2013, 15(3):233-237.

[2] Guan Yixin, Sun Xianchun. Product quality supervision system based on Internet of things, Journal of the Hebei Academy of Sciences, 2011, 28(3):70-74.

[3] Li Li. Application of two-dimensional code quality tracing system in Construction Engineering [J] Journal of China new technology and new products. 2014(7):10-13.

[4] GuoJue. Research on the evolution and risk management of the online supply chain finance model based on the third party B2B platform, Journal of Business Economics and management, 2014,267(1):13-22.

[5] He Juan. Supply chain financial service innovation based on the third party electronic trading platform -- a preliminary study of the cloud storage and its operation mode, Journal of Business Economics and management. 2012,249(7):5-13.

[6] Tu Jianping. Research on the performance evaluation of supply chain financing mode based on e-commerce platform, Journal of World management. 2013(7):182-184.

[7] Huang Shaoqing, Hu Yuefei. Supply chain finance: background, innovation and concept definition, Journal of financial research. 2009(8):194-206.

[8] Zhu Xiao. From the perspective of supply chain finance and financing of agricultural industry chain, Journal of Beijing Economics. 2013(1):55-57. 